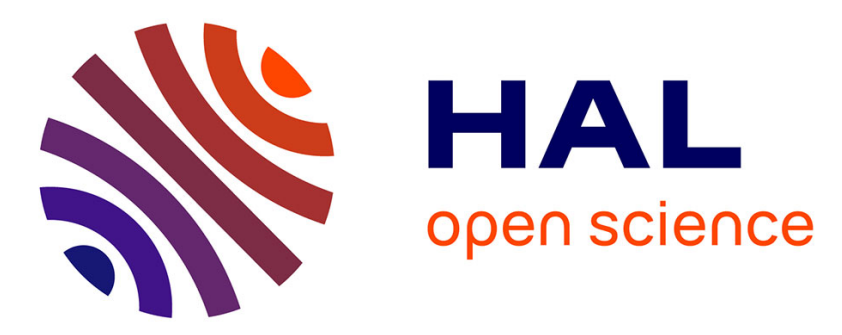

\title{
Elongated DBD with floating interelectrodes for actuators
}

\author{
A. Berendt, J. Podliński, J. Mizeraczyk
}

\section{To cite this version:}

A. Berendt, J. Podliński, J. Mizeraczyk. Elongated DBD with floating interelectrodes for actuators. European Physical Journal: Applied Physics, 2011, 55 (1), 10.1051/epjap/2011100441 . hal00719810

\section{HAL Id: hal-00719810 \\ https://hal.science/hal-00719810}

Submitted on 21 Jul 2012

HAL is a multi-disciplinary open access archive for the deposit and dissemination of scientific research documents, whether they are published or not. The documents may come from teaching and research institutions in France or abroad, or from public or private research centers.
L'archive ouverte pluridisciplinaire HAL, est destinée au dépôt et à la diffusion de documents scientifiques de niveau recherche, publiés ou non, émanant des établissements d'enseignement et de recherche français ou étrangers, des laboratoires publics ou privés. 


\title{
Elongated DBD with floating interelectrodes for actuators
}

\author{
Artur Berendt ${ }^{1}$, Janusz Podliński ${ }^{1}$, Jerzy Mizeraczyk ${ }^{1,2}$ \\ ${ }^{1}$ Centre for Plasma and Laser Engineering, The Szewalski Institute of Fluid Flow Machinery, \\ Polish Academy of Sciences, Fiszera 14, 80-952 Gdańsk, Poland \\ tel.: $+48(58) 6995122$, fax: $+48(58) 3416144$ \\ 2 Department of Marine Electronics, Gdynia Maritime University, \\ Morska 81-87, 81-225 Gdynia, Poland \\ E-mail: aberendt@imp.gda.pl
}

Abstract. In this paper the use of a floating interelectrode for dielectric barrier discharge (DBD) plasma actuators applied in aerodynamics is described. The velocity profiles of airflow generated by a single-DBD actuator with the floating interelectrode are presented. Also double-DBD and multi-DBD plasma actuators with floating interelectrodes were investigated to get a longer DBD on a dielectric surface. Obtained results show that the DBDs with floating interelectrodes are capable of extending the plasma area on the dielectric surface. The airflow induced by the successive DBD sets with floating interelectrodes in the multi-DBD actuator had the same direction enhancing the net airflow. The airflow velocity produced by the investigated multi-DBD actuator was up to $10 \mathrm{~m} / \mathrm{s}$. This suggests that muti-DBD actuators with floating interelectrodes can be attractive for many aerodynamic purposes.

\section{Introduction}

Since Roth et al [1] used "a one atmosphere uniform glow discharge surface plasma" (OAUGDP) for the boundary layer flow control [2], interest in the plasma-based devices for aerodynamic purposes has grown. OAUGDP used in the aerodynamics is a kind of surface dielectric barrier discharge (DBD) [3] established when a voltage is applied to electrodes which are asymmetrically set on the top and bottom sides of a dielectric material. Such a surface DBD induces airflow above the dielectric. An example of the plasma devices using the surface DBDs are electrohydrodynamic (EHD) plasma actuators which are capable of improving the properties of aerodynamic elements modifying airflow around them [4]. EHD plasma actuators are useful in controlling laminar-turbulent flow transition, in separation, reattachment and detachment of the flow, and in reducing drag and improving lift of airfoils. EHD plasma actuators are also used for aeroacoustic applications [5]. 
In the past ten years lots of EHD plasma actuator configurations were investigated [4]. The research effort was directed mostly towards developing the actuators composed of two plane electrodes placed asymmetrically on the opposite sides of a dielectric plate. As the dielectric ordinary glass or ceramics were used. Their thickness was around a few millimetres. The electrodes were usually made of copper or aluminium tape fixed on the surface of the dielectric plate. Typically a smooth plane electrode was used as the stressed (at high voltage, HV) electrode. However, also other shapes of the stressed electrode were investigated to enhance the DBD, for example a wire electrode [6]. In [7] we proposed to use saw-like electrodes for generating DBD in plasma actuators. As shown in [7] a DBD with saw-like electrode starts at a lower voltage, is more homogenous and produces higher velocities of airflow compared with a DBD with smooth electrode. Usually, when a high voltage is applied in a DBD actuator, a surface DBD plasma establishes on both sides of the dielectric. However, to avoid plasma on one side of the dielectric plate, the stressed or grounded electrode can be insulated (see a "classic" single-DBD set in Fig. 1, where the HV electrode is insulated). The surface plasma generated by the DBD was proved to be capable of producing electric wind which induces airflow with velocities up to several $\mathrm{m} / \mathrm{s}$, tangentially to the surface of the dielectric plate [4].

When using a "classic" single-DBD actuator set (e.g. in the form of an AC HV electrode - grounded electrode arrangement shown in Fig. 1), the plasma area expands at most to about 15 - $20 \mathrm{~mm}$ along the actuator surface. However, sometimes a larger plasma area is needed, for example, to cover a large surface on an airfoil in the streamwise direction with a DBD plasma and produce an enhanced aerodynamic effect along the airfloil (e.g. high airflow velocity). A straightforward solution is to use several "classic" single-DBD actuator set in series (Fig. 1), parallel one to each other [8-13]. However, such an arrangement requires a distance of a few centimetres between the neighbouring single-DBD actuators sets to avoid a second surface discharge between them, generated around the grounded electrode of the successive DBD set. Such a second surface discharge produces a backward airflow (toward the proceeding DBD set) that counteracts the desired airflow [9, 14]. As it is seen in Fig. 1, large areas between consecutive DBD sets are not covered by plasma when the DBD set spacing is long enough to avoid the second surface discharge and counteracting airflow. Such plasma voids are a drawback in a real scale applications. In order to get a longer DBD area in the streamwise direction on a dielectric surface, multi-DBD actuators based on three-electrode arrangement were proposed [14]. The three-electrode arrangement improved characteristics of the generated airflow, i.e. the backward airflow was eliminated and the net airflow velocity 
was increased. However, the velocity of the airflow induced by the three-electrode DBD sets (below $4 \mathrm{~m} / \mathrm{s}$ ) is not satisfactory for practical applications.

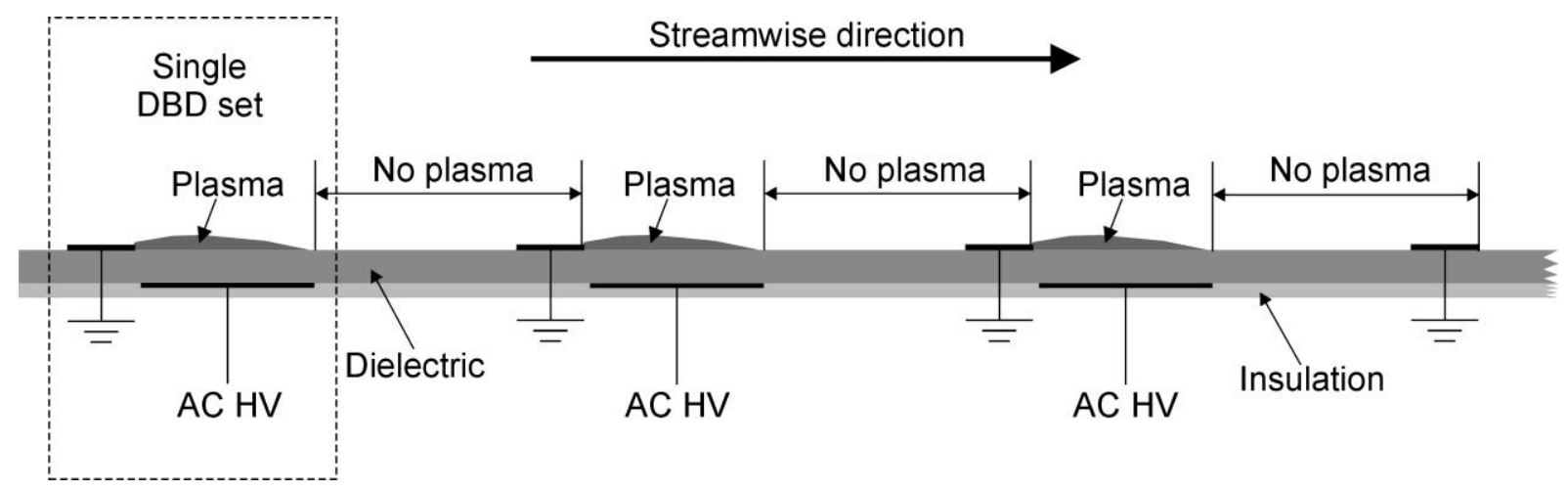

Fig. 1 Side view of the classic DBD sets used to cover a larger surface with plasma

In this paper we present floating interelectrodes for multi-DBD actuators which allow elongating the DBD plasma on the dielectric surface in the streamwise direction and eliminating the backward airflow. We also show that the use of the floating interelectrodes in multi-DBD actuators results in enhanced airflow generated above the dielectric surface.

\section{Experimental set-up}

\section{Single-DBD actuator with floating interelectrode}

The single-DBD actuator consisted of a HV electrode and a grounded electrode mounted on one side of a $2 \mathrm{~mm}$-thick glass plate (a dielectric barrier, the electric relative permittivity $\varepsilon_{\mathrm{r}}=7$ ), and of an interelectrode at floating potential placed on the opposite side of the glass plate (Fig. 2). All electrodes were made of a $50 \mu$ m-thick copper tape.

Saw-like electrodes (Figs. 3 and 6c) were used as the floating interelectrodes in all the investigated DBD actuators. In the single-DBD actuator the floating interelectrode (Fig. 3) was exposed to ambient air, the high voltage and grounded electrodes were insulated with a $50 \mu \mathrm{m}$-thick polyimide tape. The floating interelectrode and the high voltage electrode were $6 \mathrm{~mm}$ wide while the grounded electrode was $10 \mathrm{~mm}$ wide. The shift between the high voltage electrode and the floating interelectrode was $1 \mathrm{~mm}$, and between the floating interelectrode and the grounded electrode $-15 \mathrm{~mm}$. The lengths of all electrodes (in the spanwise direction) were $80 \mathrm{~mm}$. 


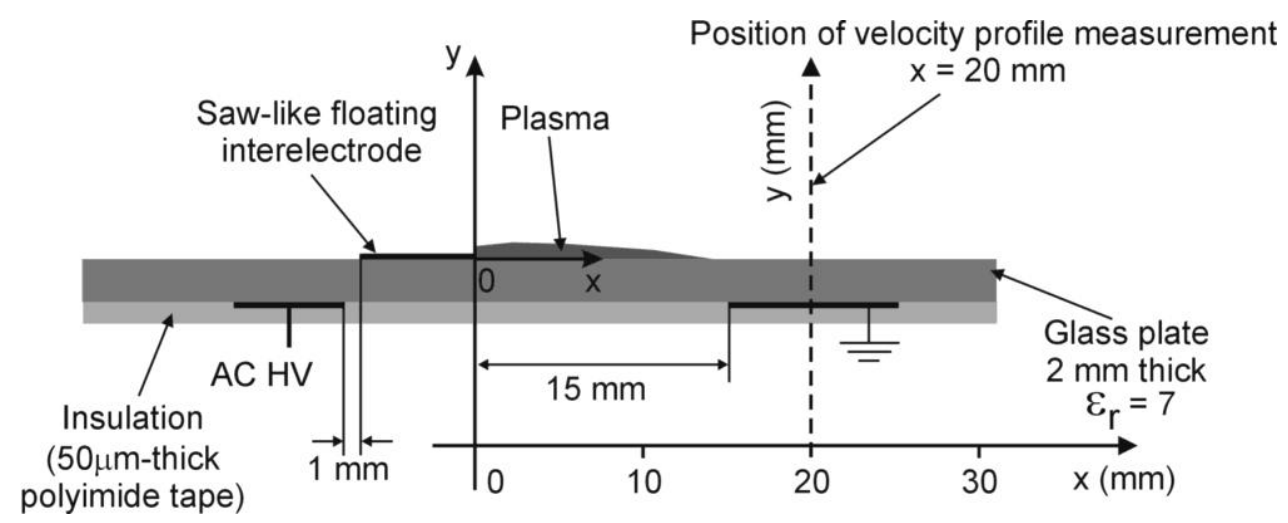

Fig. 2 Side view of the single-DBD actuator with a floating interelectrode

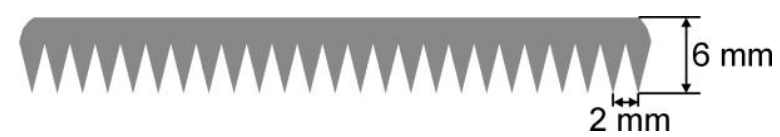

Fig. 3 A saw-like floating interelectrode used in the single-DBD actuator

Double-DBD actuator with floating interelectrode and two grounded electrodes

A double-DBD actuator was developed to produce the elongated DBD on a dielectric surface. The schematic side view of the double-DBD with a floating interelectrode and two grounded electrodes, (1) and (2), is shown in Fig. 4. In this arrangement the saw-like floating interelectrode was exposed to ambient air when the two smooth grounded electrodes and the smooth high voltage electrode were insulated with the polyimide tape. The widths of electrodes were as follows: the grounded electrodes-3 mm, the floating interelectrode $-4 \mathrm{~mm}$, and the high voltage electrode $-10 \mathrm{~mm}$. The distance between the first grounded electrode (1) and the floating interelectrode was $10 \mathrm{~mm}$. The distance between the floating interelectrode and the second grounded electrode (2) was $4 \mathrm{~mm}$. There was no shift between the first grounded electrode (1) and the high voltage electrode, as well as between the high voltage electrode and the floating interelectrode.

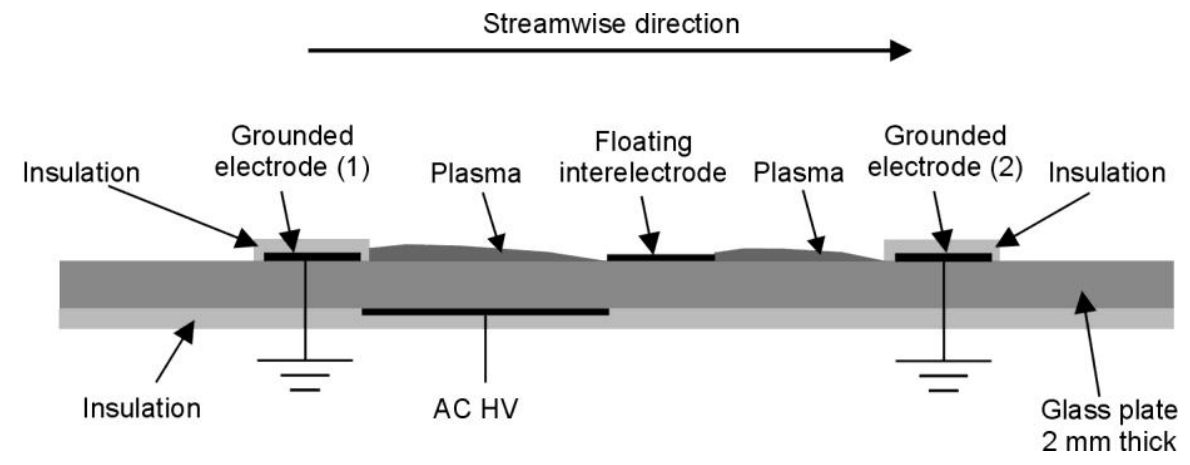

Fig. 4 Side view of the double-DBD actuator with a floating interelectrode 


\section{Multi-DBD actuator with floating interelectrodes}

Basing on the double-DBD arrangement, a multi-DBD actuator was developed (Fig.5). In the multi-DBD actuator a smooth high voltage electrodes, saw-like grounded electrodes and saw-like floating intrelectrodes, made of a $50 \mu \mathrm{m}$-thick copper tape were used (Fig. 6). We tested that a saw-like floating interelectrode consisting of a series of separated (electrically isolated) copper teeth improved homogeneity of the discharge compared with that when the saw-like floating interelectrode as presented in Fig. 3 was used.

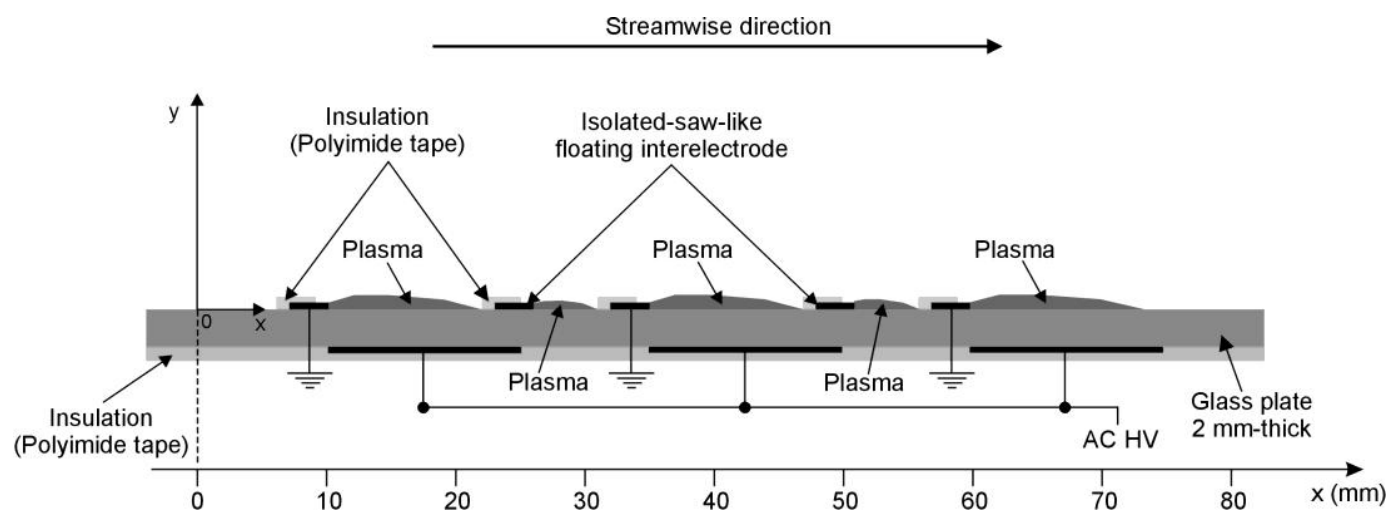

Fig. 5 Side view of the multi-DBD actuator with isolated-saw-like floating interelectrodes

a)

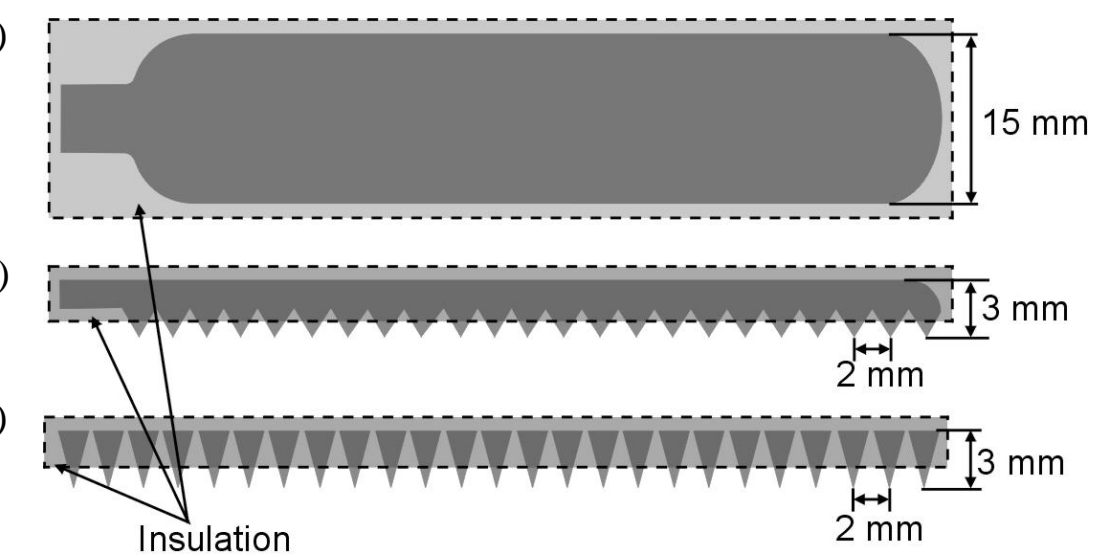

(Polyimide tape)

Fig. 6 Smooth HV electrode (a), saw-like grounded electrode (b) and isolated-saw-like floating interelectrode (c) used in the multi-DBD actuator

The floating and the grounded electrodes were on the discharge and the flow active side of the dielectric material. The high voltage electrodes insulated with the polyimide tape were fixed on the opposite side. The floating and the grounded electrodes were partially 
insulated with the polyimide tape, as shown in Fig. 6. Only the tips of saw-like teeth were uncovered. The positioning of all the electrodes with respect to each other is shown in Fig. 7. The length of the isolated-saw-like floating interelectrode was $45 \mathrm{~mm}$. The high voltage and grounded electrodes were $50 \mathrm{~mm}$ long. The high voltage electrode was $15 \mathrm{~mm}$ wide whereas the widths of the floating and the grounded electrodes were $3 \mathrm{~mm}$.

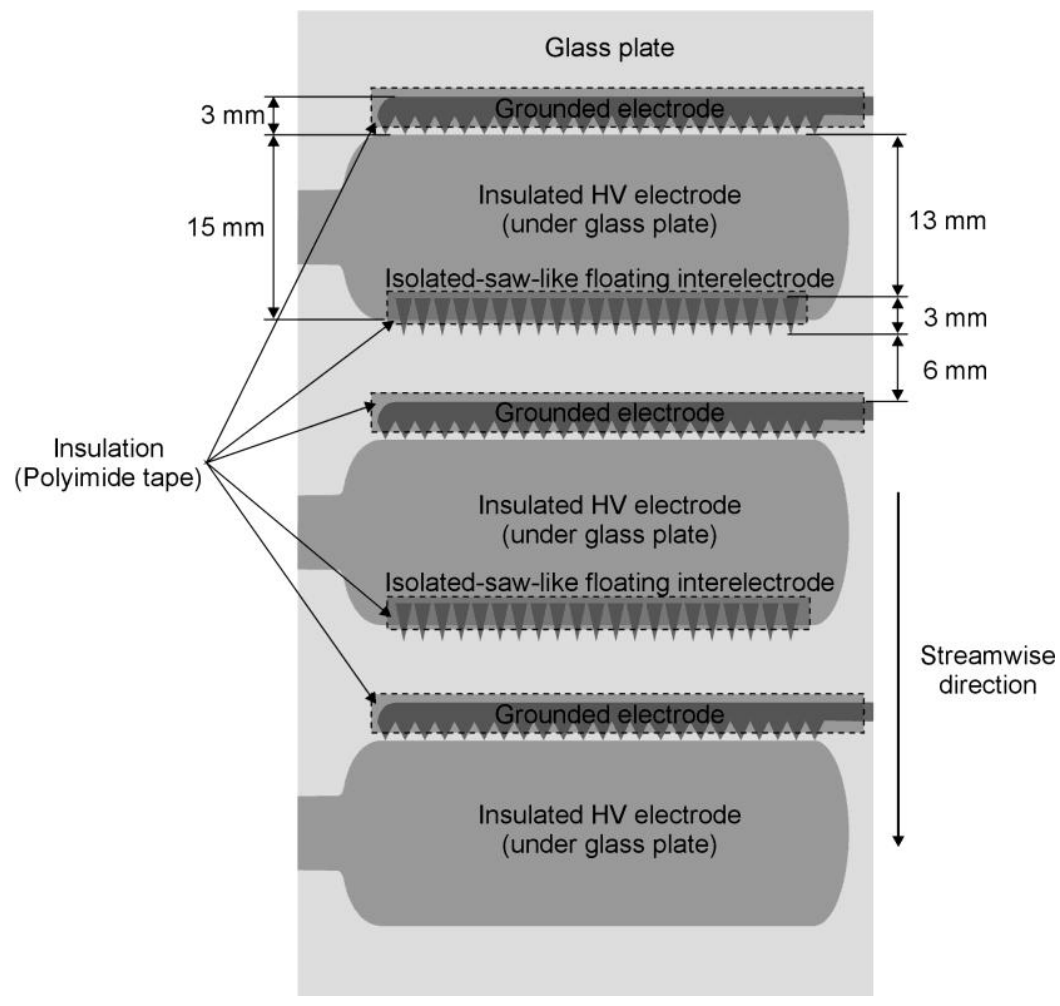

Fig. 7 Top view of the multi-DBD actuator with floating interelectrodes

\section{Experimental apparatus}

The experimental set-up for the measurements of the electric parameters of the DBD and the airflow generated by the DBD plasma actuators is presented in Fig. 8. It consists of an AC power supply, an oscilloscope, a discharge current probe, a flow channel in which the DBD actuators were placed, and a standard two-dimensional (2D) particle image velocimetry (PIV) [15] equipment for the measurements of airflow velocity fields generated above the DBD actuator.

The AC power supply was assembled from a sine-wave function generator and a HV power amplifier. The sinusoidal high voltage applied to the DBD actuators was generated by the power amplifier (TREK, model $40 / 15, \mathrm{U}_{\mathrm{pp}}$ - up to $80 \mathrm{kV}$, frequency - up to $2.5 \mathrm{kHz}$ ) which amplified sine-wave signal from the function generator METEX MS9150. The 
discharge current was measured using a Pearson current probe (Rogowski coil). The voltage and discharge current signals were monitored by an oscilloscope Tektronix DPO 3034. The voltage signal was delivered to the oscilloscope from a high-voltage probe in which the HV power amplifier was fitted. The example of the waveforms of the applied voltage and the discharge current are presented in Fig. 9.

The measurements were carried out in air at atmospheric pressure in an end-opened flow channel. At this stage of the experiment there was no externally forced airflow in the flow channel.

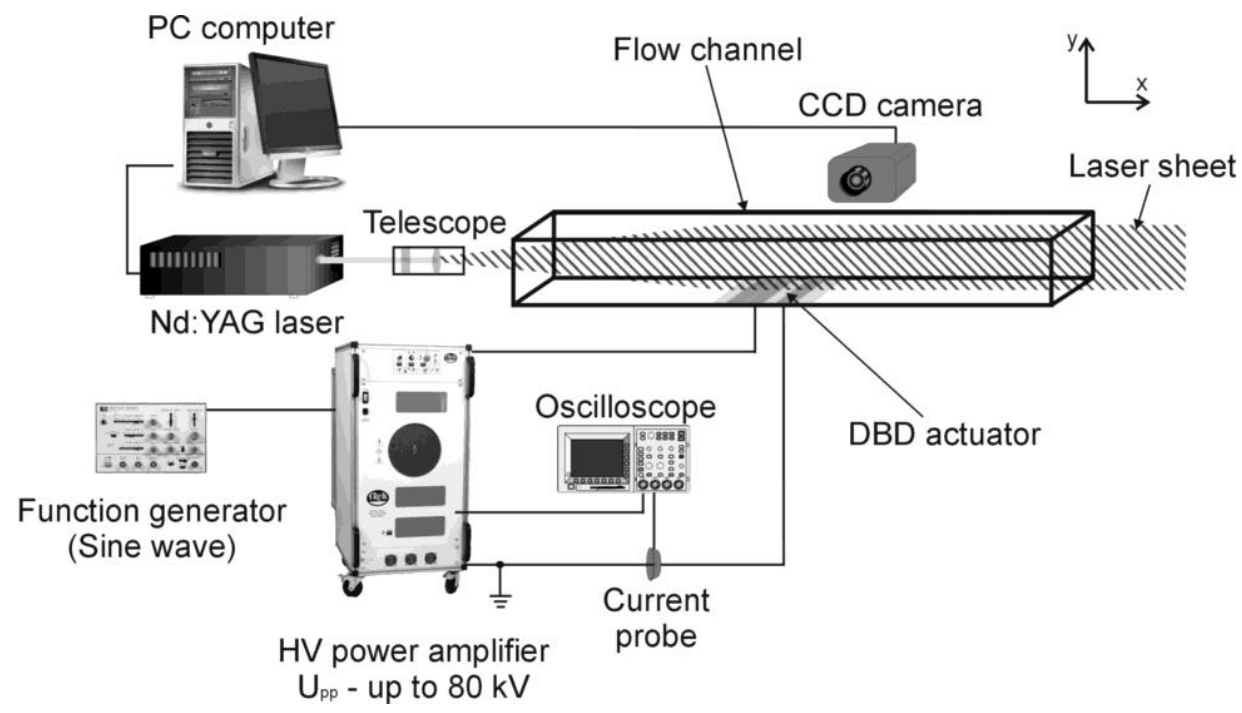

Fig. 8 Experimental set-up

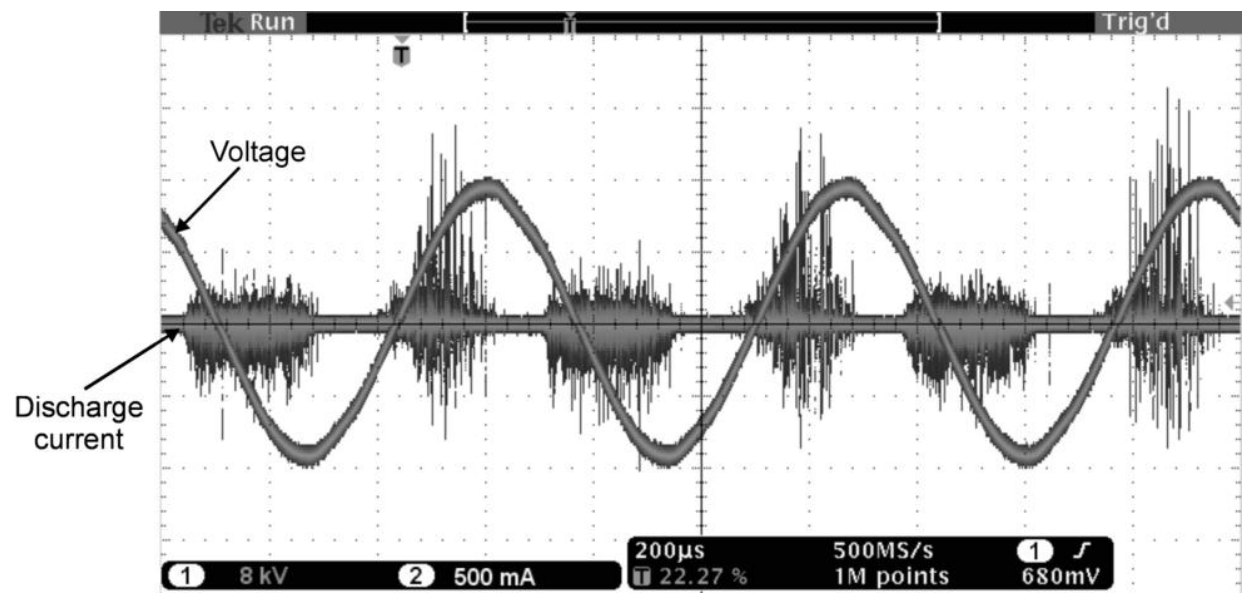

Fig. 9 Example of the voltage and current waveforms measured for a multi-DBD actuator with isolated-saw-like floating interelectrodes. The applied sine-wave voltage $\mathrm{U}_{\mathrm{pp}}=32 \mathrm{kV}$, the frequency $-1.5 \mathrm{kHz}$. 
The 2D PIV system for measuring the airflow velocity field was composed of a double Nd-YAG laser system $(\lambda=532 \mathrm{~nm})$, a cylindrical telescope, a CCD camera and a PC computer. A laser sheet shaped by the cylindrical telescope was formed above the DBD actuator. An incense smoke was used as a seed. The images of the seed particles (called a flow images) following the airflow generated by the DBD actuator were recorded by FlowSense M2 camera. The CCD camera sensor size was 1600 pixels $\times 1186$ pixels. The captured pairs of PIV images were transmitted to the PC computer for a digital analysis. The digital analysis (e.g. to compute instantaneous and time-averaged flow velocity fields) was made using Dantec Flow Manager.

The 2D PIV measurements were carried out in a plane defined by the laser sheet which was placed perpendicularly to the DBD actuator electrodes at their half-length (Fig. 8). 150 pairs of PIV instantaneous flow images were taken. Then, an adaptive cross-correlation algorithm was applied to the set of these 150 image pairs to compute 150 instantaneous flow velocity fields. Basing on these instantaneous flow velocity fields the time-averaged airflow velocity field was calculated. The interrogation window during the cross-correlation procedure was 16 pixels $\times 8$ pixels (horizontal $\times$ vertical). The overlap between neighbouring interrogation windows was $25 \%$. The acquisition rate of the pairs of PIV instantaneous airflow images was $5 \mathrm{~Hz}$, thus the total acquisition time needed for a single airflow velocity field was 30 seconds. Using the time-averaged airflow velocity fields, the airflow velocity profiles (the airflow velocity variations in the vertical direction above the DBD actuator) were determined.

\section{Results}

\section{Single-DBD actuator with floating interelectrode}

The time-averaged flow velocity field and the flow velocity profiles of an airflow induced by the single-DBD actuator with saw-like floating interelectrode, obtained from PIV measurements, are presented in Figs. 10 and 11, respectively. The observation area of the PIV measurement was $127 \mathrm{~mm} \times 47 \mathrm{~mm}$ and the spatial resolution of obtained vector fields was $0.95 \mathrm{~mm} \times 0.5 \mathrm{~mm}$. The obtained results showed that the DBD with floating interelectrode could produce an airflow above the dielectric surface with the maximum velocity of $3.4 \mathrm{~m} / \mathrm{s}$ about $1.5 \mathrm{~mm}$ above the dielectric. The maximum velocity is lower than that obtained with a "classic" single-DBD (about $5 \mathrm{~m} / \mathrm{s}$ ), however the use of the floating 
interelectrode is aimed at developing multi-DBD actuators that would have better characteristics than "classic" multi-DBD ones.

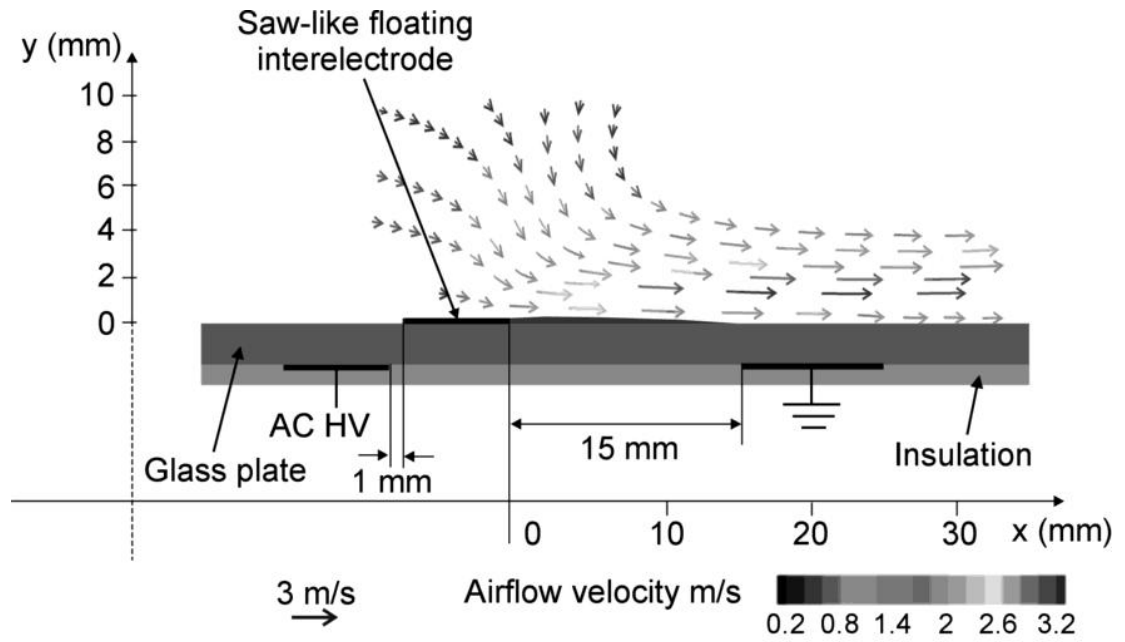

Fig. 10 Time-averaged flow velocity field of an airflow induced by the single-DBD plasma actuator with saw-like floating interelectrode (colour bar when the figure is printed in colours). The applied sine-wave voltage was $60 \mathrm{kV}_{\mathrm{pp}}$, the frequency $-1.5 \mathrm{kHz}$.

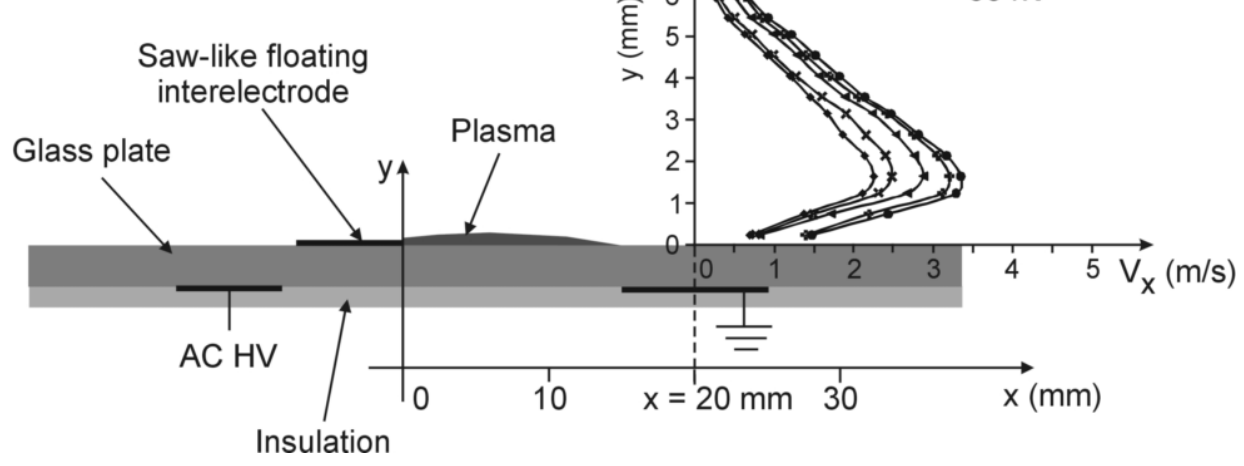

Fig. 11 Time-averaged flow velocity profiles measured $20 \mathrm{~mm}$ (at $\mathrm{x}=20 \mathrm{~mm}$ ) downstream the edge of saw-like floating interelectrode

Double-DBD with floating interelectrode

The image of the discharge generated by the double-DBD with saw-like floating interelectrode is shown in Fig. 12. The plasma was generated between the first grounded (1) 
electrode and the floating interelectrode, and between the floating interelectrode and the second grounded electrode (2). The plasma between the floating interelectrode and the second grounded electrode resembled a series of parallel "corona-like" discharges originated at the floating interelectrode tooth-tips.

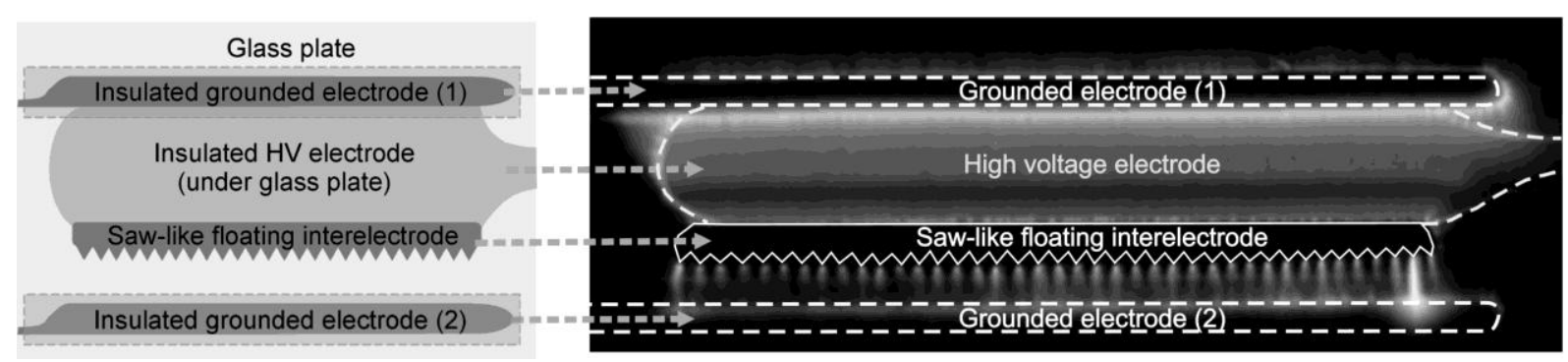

Fig. 12 Image (top view) of the discharge obtained in the double-DBD actuator with floating interelectrode. The applied sine-wave voltage was $34 \mathrm{kV}_{\mathrm{pp}}$, the frequency $-1.5 \mathrm{kHz}$. The camera exposure time was $0.5 \mathrm{~s}$.

\section{Multi-DBD actuator with floating interelectrodes}

The image of the discharge generated by the multi-DBD actuator with isolated-saw-like floating interelectrodes is shown in Fig. 13. The plasma observed for the consecutive electrode sets of the multi-DBD was similar as for the double-DBD described above. As it is seen from Fig. 13, the multi-DBD allows covering with plasma much larger area of the dielectric surface compared with the sequence of the "classic" single-DBDs (Fig. 1).

In Fig. 14 the time-averaged flow velocity field of an airflow generated by the multiDBD $\left(32 \mathrm{kV}_{\mathrm{pp}}, 1.5 \mathrm{kHz}\right)$ actuator with floating interelectrodes are presented. In this case the observation area in the PIV measurements was $87 \mathrm{~mm} \times 32 \mathrm{~mm}$ and the spatial resolution of obtained vector fields was $0.6 \mathrm{~mm} \times 0.3 \mathrm{~mm}$. The time-averaged horizontal velocity profile taken $0.3 \mathrm{~mm}$ above the dielectric surface (a), the contour velocity map (b) and the time-averaged flow velocity vector field (c) are presented in Fig. 15. 


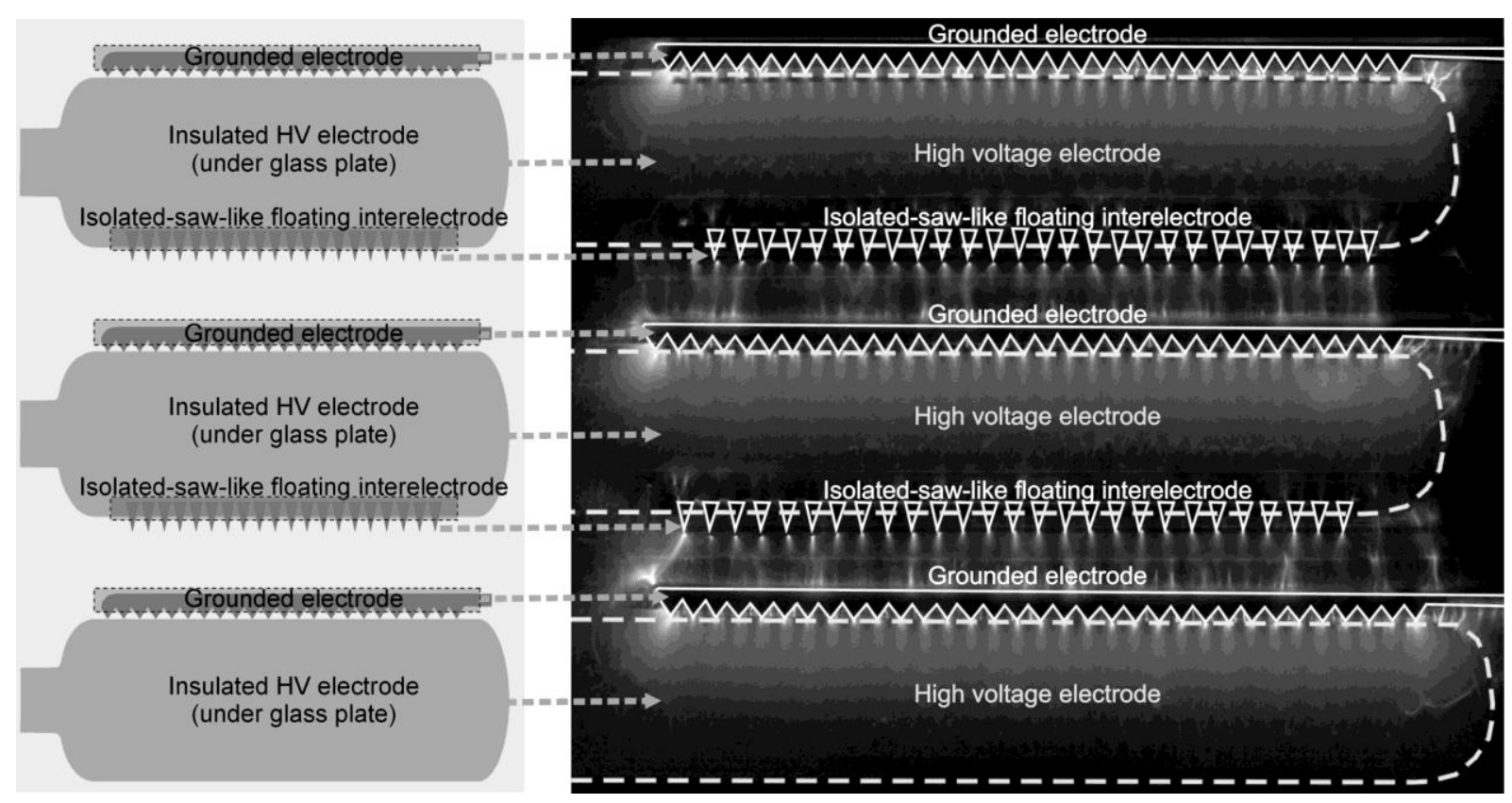

Fig. 13 Image (top view) of the discharge obtained in the multi-DBD actuator with isolated-saw-like floating interelectrodes. The applied sine-wave voltage was $32 \mathrm{kV}_{\mathrm{pp}}$, the frequency $-1.5 \mathrm{kHz}$. The camera exposure time was $0.5 \mathrm{~s}$.

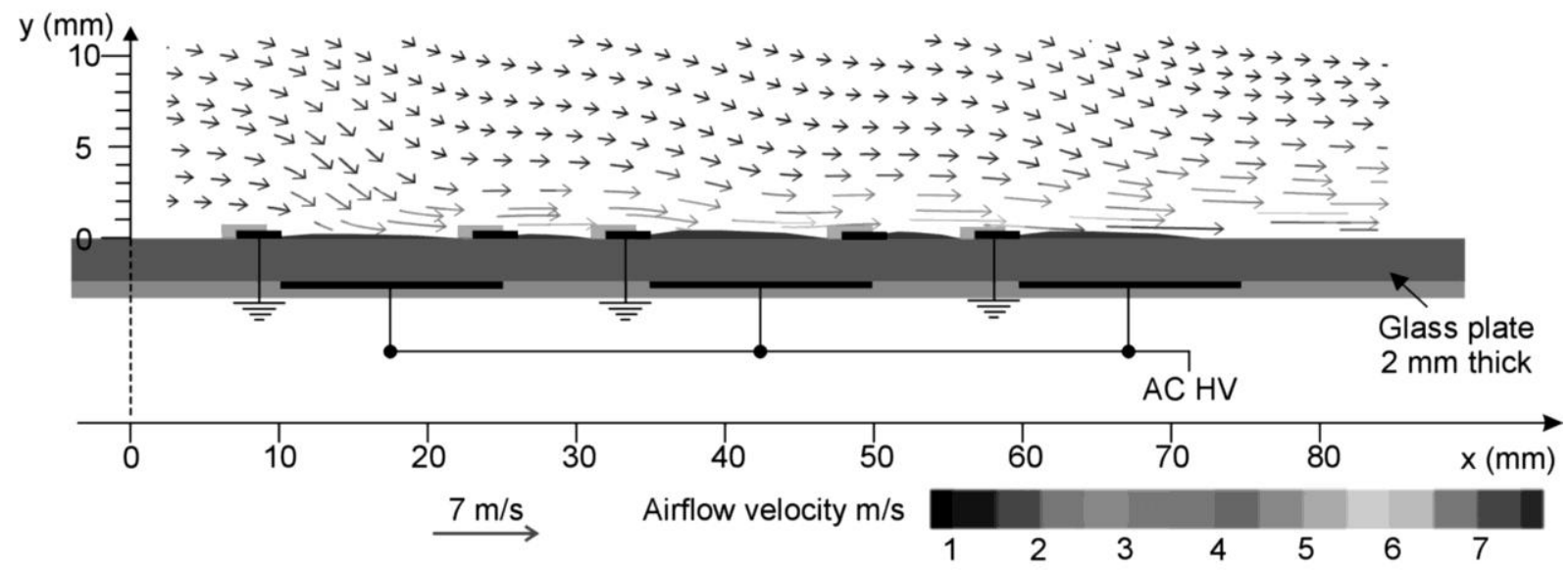

Fig. 14 Time-averaged flow velocity field of the airflow generated by the multi-DBD actuator (colour bar when the figure is printed in colours). The applied sine-wave voltage $32 \mathrm{kV}_{\mathrm{pp}}$, the frequency $-1.5 \mathrm{kHz}$.

As it is seen form Fig. 15, a significant airflow was induced by the multi-DBD actuator tangentially to the dielectric surface. The airflow was almost continuously accelerated along the consecutive DBD sets in the multi-DBD actuator (Fig. 15a). The 
backward flow or vortexes between the successive DBD sets were not observed (Figs. 15b and $15 \mathrm{c})$.

The time-averaged flow velocity profiles measured $8 \mathrm{~mm}$ downstream the last high voltage electrode of the multi-DBD actuator are presented in Fig. 16. In this case the observation area of the PIV measurements was restricted to $50 \mathrm{~mm} \times 19 \mathrm{~mm}$ in order to increase the spatial resolution of vector fields $(0.4 \mathrm{~mm} \times 0.2 \mathrm{~mm})$ and to provide a higher accuracy of the velocity measurements. The applied sine-wave voltage was $32 \mathrm{kV}_{\mathrm{pp}}$ at frequency $1.5 \mathrm{kHz}$ or $2.35 \mathrm{kHz}$. The maximum attained airflow velocity was $8.9 \mathrm{~m} / \mathrm{s}$ and $10.1 \mathrm{~m} / \mathrm{s}$ at a frequency $1.5 \mathrm{kHz}$ and $2.35 \mathrm{kHz}$, respectively.

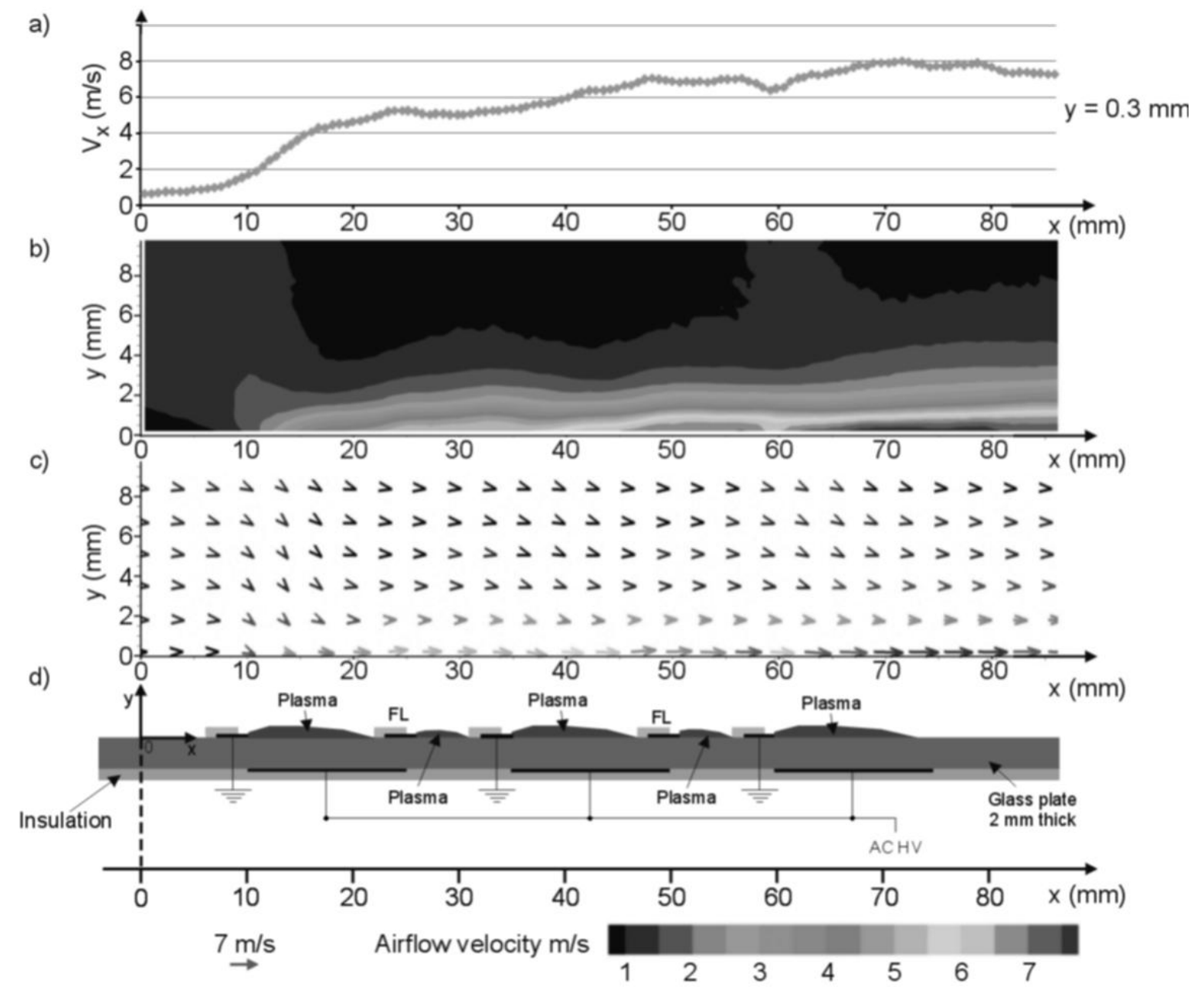

Fig. 15 The horizontal time-averaged flow velocity profile taken $0.3 \mathrm{~mm}$ above the dielectric surface (a), the contour velocity map (b) and the time-averaged flow velocity vector field (c) (colour bar when the figure is printed in colours) of the airflow produced by the multi-DBD actuator (d). The applied sine-wave voltage $32 \mathrm{kV}_{\mathrm{pp}}$, the frequency - $1.5 \mathrm{kHz}$. FL - floating interelectrode. 

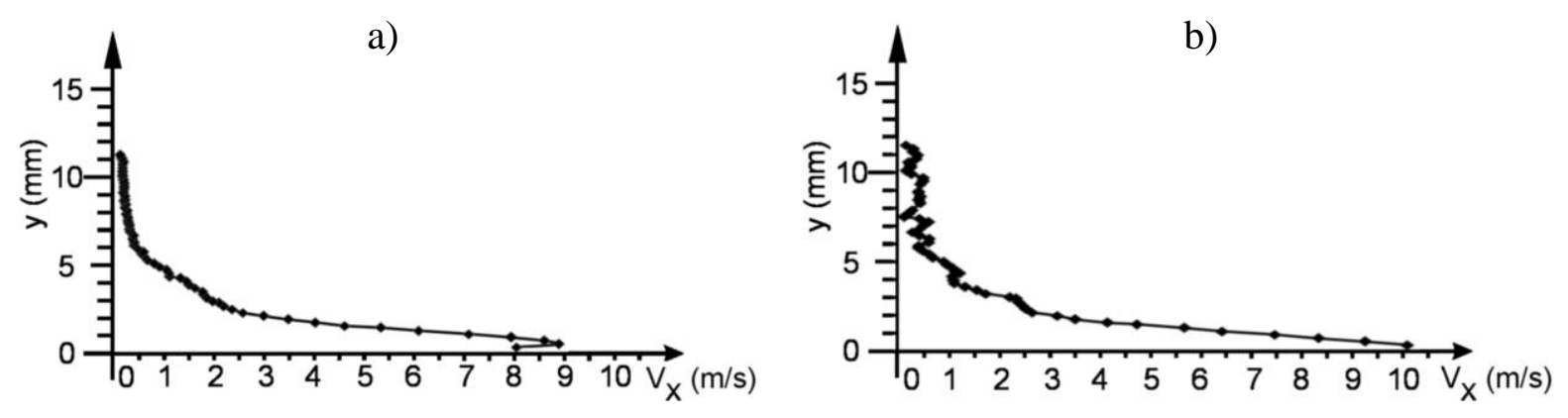

Fig. 16 Time-averaged flow velocity profiles measured $8 \mathrm{~mm}$ downstream the last high voltage electrode of the multi-DBD actuator. The applied sine-wave voltage was $32 \mathrm{kV}_{\mathrm{pp}}$, the frequency: $1.5 \mathrm{kHz}(\mathrm{a}), 2.35 \mathrm{kHz}(\mathrm{b})$.

The obtained time-averaged flow velocity profiles (Figs. 11 and 16) showed that the maximum airflow velocity above the multi-DBD actuator is closer to the actuator surface than in case of the single-DBD actuator with floating interelectrode. We think this phenomenon can be explained basing on the flow velocity field presented in Fig 14. In this figure the airflow observed near the first plasma area (x from $10 \mathrm{~mm}$ to $25 \mathrm{~mm}$ ) for $\mathrm{y}>2 \mathrm{~mm}$ is directed to the actuator surface. Then, for $y<2 \mathrm{~mm}$ the airflow turns and moves parallel to the actuator. The maximum airflow velocity downstream the first grounded electrode of multi-DBD actuator is about $1 \mathrm{~mm}$ above the actuator, similarly like in single-DBD actuator (Fig. 10). However, consecutive plasmas of the multi-DBD actuator accelerate the previously induced airflow. The biggest airflow acceleration was observed near the DBD plasma i.e. near the actuator surface. Thus, the maximum velocity of the net airflow produced by the multi-DBD actuator can be closer to the actuator surface than in case of single-DBD actuator.

\section{Summary}

A new type of the DBD with floating interelectrodes for plasma actuators was presented in this paper. The obtained results clearly proved that the single-DBD actuator with the floating interelectrode can efficiently generate an airflow above a dielectric surface. The maximum velocity of the generated airflow is lower than that obtained by the "classic" single-DBD actuator, however, the concept of the DBD with floating interelectrode allowed developing innovative multi-DBD actuators.

Using the double-DBD and the multi-DBD actuators with floating interelectrodes the generation of the plasma on a large area of the dielectric material was obtained. Each individual airflow induced by the consecutive DBD sets in the multi-DBD actuator with 
floating interelectrodes had the same direction. The backward flow in the multi-DBD actuator was absent. The airflow, tangential to the dielectric surface, was accelerated by the consecutive DBD sets to achieve a velocity above $10 \mathrm{~m} / \mathrm{s}$ at the actuator end. The above properties of the multi-DBD actuator with floating interelectrodes make this actuator superior to the "classic" multi-DBD actuators (as presented in Fig. 1). The presented multi-DBD design with floating interelectrodes is expected to be useful for real scale applications.

\section{Acknowledgement}

The research presented in this paper received funding from the European Community, Seventh Framework Programme FP7/2007-2013 under grant agreement no.: 234201 (PLASMAERO - Useful PLASMas for AEROdynamic control www.plasmaero.eu) and by the R. Szewalski Institute of Fluid Flow Machinery, Polish Academy of Sciences, Gdańsk.

\section{References}

[1] J.R. Roth, P.P. Tsai, C. Liu, M. Laroussi, P.D. Spence, United States Patent 5414324, 1995

[2] J.R. Roth, D.M. Sherman and S.P. Wilkinson, AIAA 1998-0328, in Proceedings of the 36th AIAA Aerospace Sciences Meeting and Exhibit, Reno, NV, 1998

[3] U. Kogelschatz, Plasma Chem. Plasma Process. 23, 1 (2003)

[4] E. Moreau, J. Phys. D: Appl. Phys. 40, 3 (2007)

[5] X. Huang, X. Zhang, International Journal of Aeroacoustics, 9, 4-5 (2010)

[6] A. Debien, N. Bernard, E. Moreau, in Proceedings of the $7^{\text {th }}$ Conference of the French Society of Electrostatics SFE, Monpellier, France, 2010, p.156

[7] J. Podlinski, A. Berendt, J. Mizeraczyk, in Proceedings of the $12^{\text {th }}$ International Symposium on High Pressure, Low Temperature Plasma Chemistry, Trencianske Teplice, Slovakia, 2010, p. 135

[8] J.R. Roth, R.C. M. Madhan, M. Yadav, J. Rahel and S.P. Wilkinson, AIAA 2004 0845, in Proceedings of the 42nd AIAA Aerospace Sciences Meeting and Exhibit, Reno, USA, 2004

[9] M. Forte, J. Jolibois, J. Pons, E. Moreau, G. Touchard and M. M. Cazalens, Exp. Fluids 43, 6 (2007)

[10] F. O. Thomas, A. Kozlov and T. C. Corke, AIAA J. 46, 8 (2008)

[11] J. Jolibois, M. Forte and E. Moreau, Journal of Electrostatics 66, 9-10 (2008)

[12] H. Do, W. Kim, M. .A Capelli and M. G. Mungal, Appl. Phys. Lett. 92, 7 (2008) 
[13] J. Little, M. Nishihara, I. Adamovich and M. Samimy, AIAA Paper 2009-145, in Proceedings of the 42nd AIAA Aerospace Sciences Meeting and Exhibit, Orlando, Florida, USA, 2009

[14] N. Benard, A. Mizuno and E. Moreau, J. Phys. D: Appl. Phys. 42, 23 (2009)

[15] M. Raffel, Ch.E. Willert, J. Kompenhans, Particle Image Velocimetry, A practical guide, Springer-Verlag Berlin Heidelberg, 2007 